\title{
Epithelial-Derived Inflammation Disrupts Elastin Assembly and Alters Saccular Stage Lung Development
}

John T. Benjamin, ${ }^{*}$ Riet van der Meer, ${ }^{*}$ Amanda M. Im, ${ }^{*}$ Erin J. Plosa, ${ }^{*}$ Rinat Zaynagetdinov, ${ }^{\dagger}$ Ankita Burman, ${ }^{\dagger}$ Madeline E. Havrilla, ${ }^{*}$ Linda A. Gleaves, ${ }^{\dagger}$ Vasiliy V. Polosukhin, ${ }^{\dagger}$ Gail H. Deutsch, Hiromi Yanagisawa, ${ }^{\ddagger}$ Jeffrey M. Davidson, Lawrence S. Prince, $\|$ Lisa R. Young, ${ }^{\dagger * * \dagger \dagger}$ and Timothy S. Blackwell ${ }^{\dagger, \dagger \dagger+\$ \S S ~}$

From the Department of Pediatrics, * Division of Neonatology, the Department of Medicine, ${ }^{\dagger}$ Division of Allergy, Pulmonary and Critical Care Medicine, the Department of Pathology, Microbiology and Immunology, " the Department of Pediatrics, ** Division of Pulmonary Medicine, the Department of Cell and Developmental Biology, ${ }^{\dagger}$ and the Department of Cancer Biology, ${ }^{\ddagger \ddagger}$ Vanderbilt University Medical Center, Nashville, Tennessee; the Department of Pathology, ${ }^{\ddagger}$ Seattle Children’s Hospital, Seattle, Washington; the Department of Molecular Biology, ${ }^{\S}$ University of Texas Southwestern Medical Center, Dallas, Texas; the Department of Pediatrics," Division of Neonatology, University of California-San Diego, San Diego, California; and the Nashville Veterans Affairs Medical Center, ${ }^{\S \S}$ Nashville, Tennessee

Accepted for publication February 23, 2016.

Address correspondence to John T. Benjamin, M.D., M.P.H., Monroe Carell Jr. Children's Hospital, Vanderbilt University Medical Center, 2215 B Garland Ave., 1105A Light Hall, Nashville, TN 37232. E-mail: john. benjamin@vanderbilt.edu.

\begin{abstract}
The highly orchestrated interactions between the epithelium and mesenchyme required for normal lung development can be disrupted by perinatal inflammation in preterm infants, although the mechanisms are incompletely understood. We used transgenic (inhibitory $\kappa B$ kinase $\beta$ transactivated) mice that conditionally express an activator of the NF- $\kappa B$ pathway in airway epithelium to investigate the impact of epithelial-derived inflammation during lung development. Epithelial NF- $\kappa$ B activation selectively impaired saccular stage lung development, with a phenotype comprising rapidly progressive distal airspace dilation, impaired gas exchange, and perinatal lethality. Epithelial-derived inflammation resulted in disrupted elastic fiber organization and down-regulation of elastin assembly components, including fibulins 4 and 5, lysyl oxidase like-1, and fibrillin-1. Fibulin-5 expression by saccular stage lung fibroblasts was consistently inhibited by treatment with bronchoalveolar lavage fluid from inhibitory $\kappa B$ kinase $\beta$ transactivated mice, Escherichia coli lipopolysaccharide, or tracheal aspirates from preterm infants exposed to chorioamnionitis. Expression of a dominant NF- $\kappa B$ inhibitor in fibroblasts restored fibulin- 5 expression after lipopolysaccharide treatment, whereas reconstitution of fibulin- 5 rescued extracellular elastin assembly by saccular stage lung fibroblasts. Elastin organization was disrupted in saccular stage lungs of preterm infants exposed to systemic inflammation. Our study reveals a critical window for elastin assembly during the saccular stage that is disrupted by inflammatory signaling and could be amenable to interventions that restore elastic fiber assembly in the developing lung. (Am J Pathol 2016, 186: 1786-1800; http://dx.doi.org/10.1016/j.ajpath.2016.02.016)
\end{abstract}

Interactions between the epithelium and mesenchyme drive critical molecular processes important for mammalian lung development. ${ }^{1-3}$ During the initial stages of lung development, epithelium-lined airways undergo branching morphogenesis and divide and grow into the surrounding mesenchyme, a process that is completed in the canalicular stage. ${ }^{4}$ Subsequently, during the saccular stage, mesenchymal differentiation and remodeling of the extracellular matrix (ECM) results in the expansion of terminal airspaces, forming respiratory saccules, which are the early gas-exchange units
Supported by a Vanderbilt University Turner-Hazinski Award (J.T.B.) and PROP scholars award, sub-awards U01 HL101794 (J.T.B.) and R01 HL119503 (L.R.Y.); Department of Veterans Affairs Merit Review grant 1I01BX002378 (T.S.B.); and NIH grants HL085317 and HL092870 (T.S.B.). Electron microscopy imaging was performed in part through the use of the Vanderbilt University Medical Center Cell Imaging Shared Resource (supported by NIH grants CA68485, DK20593, DK58404, DK59637, and EY08126).

Disclosures: None declared.

Current address of H.Y., Life Science Center, Tsukuba Advanced Research Alliance, University of Tsukuba, Japan. 
in the immature lung. ${ }^{5}$ Many preterm infants are born at a time when their lungs have just begun the saccular stage of development. In these infants, exposure to perinatal inflammation disrupts lung development, resulting in respiratory failure and persistent pulmonary dysfunction. ${ }^{6}$

Both clinical studies and animal modeling suggest that chorioamnionitis (infection/inflammation of the placenta and amniotic membranes) frequently results in preterm birth $^{7-9}$ and that fetal exposure to amniotic inflammation results in abnormal saccular stage lung development. ${ }^{10,11}$ In the lung, epithelial cells serve a critical barrier function but can also activate the innate immune system. ${ }^{12,13}$ In the setting of chorioamnionitis, the airway epithelium is thus positioned to be the initial responder to microbial products in the fetal lung, triggering an inflammatory process that could disrupt the highly orchestrated process of lung development.

The master transcription factor NF- $\kappa \mathrm{B}$ regulates innate immune responses in the lung, ${ }^{14}$ and NF- $\kappa \mathrm{B}$ activation has been associated with abnormal lung development in experimental models. ${ }^{15,16}$ In a mouse explant model of lung development, activation of NF- $\mathrm{BB}$ in the mesenchyme was reported to alter branching morphogenesis. ${ }^{17}$ Similarly, targeted activation of NF- $\kappa \mathrm{B}$ in fetal lung macrophages impairs airway branching. ${ }^{16}$ In contrast, during alveolarization, constitutive NF- $\kappa$ B activation was found in neonatal mouse lung endothelial cells, and its pharmacologic inhibition resulted in abnormal development. ${ }^{18}$ Thus, NF- $\kappa \mathrm{B}$ activation may have both cell type-and developmental stage-specific effects in the premature lung. The consequences of airway epithelial NF- $\kappa \mathrm{B}$ activation during different stages of lung morphogenesis have not been investigated.

To test the hypothesis that the airway epithelium plays a critical role in mediating the effects of fetal inflammation on lung development, we used a previously described transgenic mouse model in which activated IкB kinase $\beta$ (IKK $\beta$ ) is conditionally expressed in the airway epithelium [inhibitory $\kappa \mathrm{B}$ kinase $\beta$ transactivated (IKTA) mice] to activate NF- $\mathrm{B}$ signaling. ${ }^{19}$ Our data in this work demonstrate that the activation of innate immune signaling in the airway epithelium within a sensitive developmental window during the saccular stage results in deleterious changes to ECM organization, thereby identifying new mechanisms by which inflammation alters structure and function in the developing preterm lung.

\section{Materials and Methods}

\section{Study Approval}

Animal experiments were approved by the Vanderbilt University Institutional Animal Care and Utilization Committee (Nashville, TN). The protocol for the collection of tracheal aspirates (TAs) was approved by the Institutional Review Board at Vanderbilt University Medical Center (protocol 090910). Autopsy lung sections were obtained using a protocol approved by the Institutional Review Board at Seattle Children's Hospital (Seattle, WA) (protocol 13209).

\section{Reagents}

Antibodies for Western blot analysis and immunostaining were anti-FLAG antibody (600-403-383) from Rockland Immunochemicals (Limerick, PA), anti-tropoelastin antibody (PR 385) from Elastin Products Company (Owensville, MO), anti-green fluorescent protein (GFP) antibody (AB3080) from EMD Millipore (Billerica, MA), antifibulin-5 antibody (ab109428) from Abcam (Cambridge, MA), anti- $\beta$-actin antibody (A5316) from Sigma-Aldrich (St. Louis, MO), anti-Gr-1/Ly-6G antibody (MAB1037) from R\&D Systems (Minneapolis, MN), anti-E-cadherin (13-1900) from Life Technologies (Carlsbad, CA), and p-NF- $\kappa$ B p65 antibody (SC-101749) and Alexa-conjugated secondary antibodies from Santa Cruz Biotechnology (Dallas, TX). Rabbit polyclonal anti-fibulin-5 antibody (BSYN 1923) and adenovirus-encoding fibulin-5 or GFP were generous gifts from Dr. Yanagisawa. Recombinant human fibulin-5 was from R\&D Systems. ProLong Gold mounting media with DAPI and TO-PRO-3 were from Life Science Technologies (Grand Island, NY). Escherichia coli lipopolysaccharide (LPS) (O55:B5) was purchased from Sigma-Aldrich.

\section{Mouse Models}

We have previously reported the generation of transgenic mice expressing a FLAG-tagged form of activated human IKK $\beta$ under the control of seven repeats of the tetracycline operator-minimal CMV promoter and a tetracyclinecontrolled transcription silencer under the control of the Clara cell $10 \mathrm{kDa}(\mathrm{CClO})$ promoter, in which both transgenes are transmitted as a single block. ${ }^{19,20}$ To selectively activate IKK $\beta$ and hence NF- $\mathrm{B}$ in the airway epithelium, hemizygous male mice that contain both transgenes were crossed with homozygous female mice expressing reverse tetracycline transactivator (rtTA) under the control of the CC10 promoter (a gift from Dr. Jeffrey Whitsett). Approximately half of the pups from these matings expressed all three transgenes, thereby enabling the activation of NF- $\kappa \mathrm{B}$ in the airway epithelium after treatment with doxycycline (Dox). These mice were designated IKTA mice, and the remaining pups in each litter that expressed only the CC10-rtTA transgene were used as littermate controls. For transgene activation in fetal or neonatal lungs, pregnant or lactating dams were administered $1 \mathrm{~g} / \mathrm{L}$ of Dox (Sigma-Aldrich) in drinking water. In all experiments, the pregnant/lactating dams lacked the constitutively active $\operatorname{IKK} \beta$ (cIKK $\beta$ ) transgene such that Dox did not lead to NF$\kappa \mathrm{B}$ activation in the dams. In some experiments, we used NF- $\kappa \mathrm{B}-\mathrm{GFP}-$ luciferase mice, a NF- $\kappa \mathrm{B}$ reporter mouse strain that expresses a GFP/luciferase fusion protein with $\mathrm{NF}-\kappa \mathrm{B}$ activation. ${ }^{21}$ 


\section{0xygen Saturation Measurement in PN2 Mouse Pups}

Arterial oxygen saturation was measured using a small animal pulse oximeter (MouseOx; Starr Life Sciences, Oakmont, PA) using standard methods. Briefly, a MouseOx collar sensor was placed on nonanesthetized pups, and after a brief period for signal equilibration, oxygen saturation was determined. Oxygen saturation readings were repeated thrice in each animal over a 5-minute period, and the mean value from these three readings was recorded as the final oxygen saturation.

\section{Histologic Examination, Immunostaining, and Microscopy}

Fetal and neonatal lungs were isolated and fixed overnight in $10 \%$ formalin before paraffin embedding. Hematoxylin and eosin staining of paraffin sections was performed using standard methods, and images of hematoxylin and eosinstained sections were obtained using a bright-field microscope. For immunostaining, paraffin sections (5 $\mu \mathrm{m}$ thick) were rehydrated and subjected to a brief period of antigen retrieval using citrated buffer ( $\mathrm{pH}$ 6.5) followed by sequential incubation with the primary antibody and appropriate biotinylated secondary antibodies. Staining was then detected using NovaRED reagents (Vector Laboratories, Burlingame, CA). NovaRED-stained sections were briefly counterstained with hematoxylin before imaging using a bright-field microscope.

For immunofluorescence imaging of lung sections, isolated lungs were first processed in increasing concentrations of sucrose, frozen in Tissue-Tek optimal cutting temperature solution (Sakura, Torrance, CA), and stored at $-80^{\circ} \mathrm{C}$. Cryostat sections were briefly fixed in $4 \%$ paraformaldehyde (Electron Microscopy Sciences, Hatfield, PA) and permeabilized with $0.1 \%$ Triton X-100 (Thermo Fisher Scientific, Grand Island, NY). After overnight incubation with the primary antibody, sections were incubated with Alexaconjugated secondary antibodies before imaging with an inverted fluorescent microscope (Olympus, Center Valley, PA) or an SPE laser scanning confocal microscope (Leica Microsystems, Buffalo Grove, IL). For fluorescent imaging of lung fibroblasts, cells plated in chamber slides were fixed with $4 \%$ paraformaldehyde, permeabilized with $0.1 \%$ Triton $\mathrm{X}-100$, blocked in $5 \%$ donkey serum, and subsequently incubated overnight with the primary antibody. Cells were then incubated with Alexa-conjugated secondary antibodies, stained with DAPI, and imaged using an inverted fluorescent microscope.

\section{Hart's Elastin Staining}

Elastic fibers in lung sections were localized using Hart's elastin staining techniques as detailed previously. ${ }^{22}$ Briefly, after rehydration, paraffin-embedded lung sections were incubated overnight with resorcin-fuchsin (Electron
Microscopy Sciences) to stain elastic fibers. Counterstaining of elastin-stained sections was performed using tartrazine in saturated picric acid (Electron Microscopy Sciences). Slides were then imaged using a bright-field microscope.

\section{Electron Microscopy}

Murine lungs were minced into $0.5-\mathrm{mm}^{3}$ pieces, fixed in $3 \%$ glutaraldehyde, and stained with tannic acid and osmium tetroxide. Fixed and stained lungs were subsequently dehydrated using a graded series of ethanol and counterstained with propylene oxide before embedding in Epon. All chemicals used for processing lung samples for electron microscopy were purchased from Electron Microscopy Sciences. Epon resin was purchased from Polysciences (Warrington, PA). Thin sections were cut and imaged using an FEI Tecnai T12 transmission electron microscope (FEI, Hillsboro, OR) at the Vanderbilt cell-imaging shared resource.

\section{Bronchoalveolar Lavage Collection}

After euthanasia of adult mice, tracheostomy was performed, a 20-gauge blunt-tipped catheter was secured in the trachea, and three 1-mL aliquots of sterile normal saline were sequentially instilled and aspirated. The fluid collected from the three aspirations was pooled and centrifuged at $500 \times g$ for 10 minutes at $4^{\circ} \mathrm{C}$ to separate the supernatant from cells. The supernatant was then aliquoted and stored at $-80^{\circ} \mathrm{C}$ for future use.

\section{Mouse Lung Fibroblast Isolation and Culture}

Mouse lung fibroblasts were isolated using a modification of previously described methods. ${ }^{23,24}$ Briefly, neonatal mouse lungs were first perfused with sterile phosphate-buffered saline and removed en bloc. Collected lungs were dissected, finely minced, and enzymatically digested for a brief period at $37^{\circ} \mathrm{C}$ in Dulbecco's modified Eagle's medium containing collagenase type I $(0.5 \mathrm{mg} / \mathrm{mL}$; SigmaAldrich) and collagenase type IA $(0.5 \mathrm{mg} / \mathrm{mL}$; Sigma Aldrich), followed by pipetting to mechanically disperse lung tissue. The resulting cell suspension was then collected by centrifugation, resuspended in culture medium, and sequentially filtered through 100-, 70-, and 20- $\mu \mathrm{m}$ sterile filters. The filtrate from the $20-\mu \mathrm{m}$ filter was plated on 100 mm cell culture dishes and cultured in Dulbecco's modified Eagle's medium with $10 \%$ fetal calf serum, passaged and cryopreserved if needed for later use. For all experiments using NF- $\mathrm{B}-\mathrm{GFP}-$ luciferase fibroblasts, passage 2 or 3 cells were first cultured in 12-well culture plates or chamber slides in Dulbecco's modified Eagle's medium with $10 \%$ fetal calf serum for 48 hours and then exposed to cell culture treatments in serum-free medium for an additional 24 to 48 hours before RNA extraction or fixation.

For NF- $\kappa \mathrm{B}$ pathway-blocking experiments, fibroblasts were cultured for 48 hours in the presence or absence of adenovirus encoding a dominant-negative $\mathrm{I} \kappa \mathrm{B}$ mutant 
$\left(3 \times 10^{8}\right.$ plaque-forming units per $\left.1 \mathrm{~mL}\right)$ or Cre recombinase (as a control).

\section{In Vitro Fibulin-5 Rescue Experiments}

Fibroblasts were cultured with $3 \mu \mathrm{g} / \mathrm{mL}$ recombinant human fibulin-5 or adenovirus-encoding V5-epitope-tagged fibulin-5 $\left(3.2 \times 10^{7}\right.$ plaque-forming units per $\left.1 \mathrm{~mL}\right)$ for a 24-hour period in the presence of LPS or TAs $(50 \mu \mathrm{L}$ of TA per 500 $\mu \mathrm{L}$ of culture medium) in serum-free conditions. Control experiments were performed using adenovirus-encoding GFP or Cre recombinase. After exposure to adenoviral vectors, cells were washed with phosphate-buffered saline, and fresh serum-free culture medium (with or without LPS or TA) was replaced for an additional 24 hours.

\section{Morphometry and Image Analysis}

For morphometric evaluation of mouse lung sections, TIFF images of hematoxylin and eosin-stained sections were first imported into ImageJ software version $1.49 \mathrm{o}$ (NIH, Bethesda, MD). Airway branching was then quantified by a count of the number of completely enclosed distal airspaces per high-power field. To determine the mean distal airspace area, the airspace area of each distal saccule was manually determined and averaged across the entire imaged field. To quantify the number of neutrophils in IKTA and control lungs, immunostaining was performed with Gr-1/ Ly-6G antibodies, and lung sections were imaged at $\times 400$ magnification. The number of Gr-1-positive cells in at least four lung fields in each section (from each of four mice per group) was determined. To determine the proportion of the distal lung parenchyma occupied by elastic fibers in Hart's elastin-stained sections, distal lung parenchyma was first delineated in each TIFF image by manual subtraction of the areas occupied by large airways, blood vessels, and distal airspaces from the total image area. The area occupied by insoluble cross-linked elastin was then determined after thresholding for elastin stain color and expressed as a percentage of pixels above threshold.

For quantification of the in vitro elastin network organized by lung fibroblasts, cultured fibroblasts were immunostained for elastin using standard techniques as detailed in Histologic Examination, Immunostaining, and Microscopy and imaged using an inverted fluorescence microscope. The area occupied by elastin fluorescence was then manually identified in each image and expressed as a percentage of total image area. At least 15 to 20 random microscopic fields were imaged and quantified per treatment condition. Images were analyzed using ImageJ software.

\section{Real-Time Quantitative PCR}

Total RNA was isolated from fetal and neonatal lungs or lung fibroblasts with TRIzol reagent (Life Science Technologies) using standard procedures. First strand cDNA was synthesized using oligo-dT primers and Moloney murine leukemia virus reverse transcriptase (Superscript II; InvitroGen, Grand Island, NY). PCR primers were designed using PrimerQuest design tool (Integrated DNA Technologies, Coralville, IA; https://www.idtdna.com/Primerquest/ Home/Index). The sequences of the primers used in this study were as follows: Il6, 5'-AAGAGACTTCCATCCAGTTGCC-3' (forward), 5'-TGAAGTCTCCTCTCCGGACT-3' (reverse); Ill b, 5'-ACAGAATATCAACCAACAAGTGATATTCTC-3' (forward), 5'-GATTCTTTCCTTTGAGGCCCA-3' (reverse); Cxcll, 5'-CCGAAGTCATAGCCACACTCAA-3' (forward), 5'-GCAGTCTGTCTTCTTTCTCCGTTAC-3' (reverse); Ccl2, 5'-TGGCTCAGCCAGATGCAG-3' (forward), 5'-GGTGATCCTCTTGTAGCTCTCCAG-3' (reverse); Tnf, 5'-GACCCTCACACTCAGATCATCTTCT-3' (forward), 5'-CCACTTGGTTTGCTACGA-3' (reverse); Gapdh, 5'-TGAAGGTCGGTGTGAACGG-3' (forward), 5'-CGTGAGTGGAGTCATACTGGAA- $3^{\prime}$ (reverse); Eln, 5'-CTGCCAAAGCTGCCAAATAC- $3^{\prime}$ (forward), 5'-CCAACACCATAGCCAGGAAA-3' (reverse); Fbln4, 5'-CATAACCTTCCTGGCTCCTAC-3' (forward), 5'-GCGGTAACGACACTCATCTAT-3' (reverse); Fbln5, 5'-TGTCAACACCTATGGCTCTTTC-3' (forward), 5'-GAAGCTGCACTCGTCCATATC-3' (reverse); Lox, 5'-CAAGGGACATCGGACTTCTTAC-3' (forward), 5'-TGGCATCAAGCAGGTCATAG-3' (reverse); Loxl1, 5'-CTATGACCTCCGAGTGCTATTG-3' (forward), 5'-TCGTCCATGCTGTGGTAATG-3' (reverse); Fbnl, 5'-CAGGCTCTTCTGTGTCGATATT- $3^{\prime}$ (forward), 5'-TGGCTGACAGCTACATTCATAG-3' (reverse); and Fbn2, 5'-GGAGTATCGCTGTCTCTGTTATG-3' (forward), 5'-GATTCAGGTCACACTCGTTCA-3' (reverse). Two-step real-time PCR was performed using an IQ5 thermocycler and SYBR Green detection system (Bio-Rad, Hercules, CA). Gene expression was normalized to Gapdh in each sample. For all PCR experiments, fold-change in gene expression was calculated using the $2^{-\Delta \Delta \mathrm{C}_{\mathrm{T}}}$ method. ${ }^{25}$

\section{Immunoblot Assay and Densitometry Analysis}

Lung tissue was homogenized in radioimmunoprecipitation assay buffer with a protease and phosphatase inhibitor cocktail (Sigma-Aldrich), and total protein was quantified using a bicinchoninic acid protein assay kit (Thermo Fisher Scientific). Equal amounts of extracted protein from each sample were separated on a polyacrylamide gel and subsequently transferred to a polyvinylidene difluoride membrane (Bio$\mathrm{Rad})$. After a brief period of blocking with $5 \%$ milk, membranes were incubated with primary and secondary antibodies before chemiluminescence detection. Blots were detected using the ECL-Plus chemiluminescence detection system (Thermo Fisher Scientific) and imaged using a Kodak X-Omat 2000 imaging system (Eastman Kodak Company, Rochester, NY). For densitometry, TIFF images of blots were imported into ImageJ software and analyzed using standard methods. 


\section{Quantification of Total Lung Collagen Content}

Total soluble collagen content of the whole right lung was quantified using the Sircol assay (Biocolor, Carrickfergus, UK) according to the manufacturer's instructions. Briefly, the right lung was homogenized in $0.5 \mathrm{~N}$ acetic acid with $0.1 \mathrm{mg} / \mathrm{mL}$ pepsin and incubated overnight at $4^{\circ} \mathrm{C}$. The homogenate was centrifuged and the supernatant was used in the assay. Fifty microliters of the supernatant was incubated with the Sircol dye for 30 minutes. Samples were then centrifuged and unbound dye solution was removed. The collagen-bound dye pellet was washed multiple times with ice-cold acid-salt buffer and then solubilized in alkali reagent. Absorbance was then measured at $555 \mathrm{~nm}$, and OD values were calibrated against the collagen standard provided by the manufacturer.

\section{Lung Elastase Assay}

Mouse lungs were homogenized in phosphate-buffered saline and centrifuged at $1000 \times g$ for 10 minutes at $4{ }^{\circ} \mathrm{C}$. The total elastase content of the supernatant was measured in duplicate using the EnzChek Elastase assay kit (Molecular Probes, Grand Island, NY) as per the manufacturer's suggested methods. The protein content of each collected sample was measured using a bicinchoninic acid assay kit (Thermo Fisher Scientific). Elastase activity was then normalized to the total protein content of each sample.

\section{Desmosine Enzyme-Linked Immunosorbent Assay}

Desmosine enzyme-linked immunosorbent assay kits were purchased from American Research Products (Waltham, MA) and used per the manufacturer's suggested methods. Each sample was measured in duplicate. Measured OD values were imported into Prism software version 6.0 (GraphPad, La Jolla, CA), standard curves were plotted, and concentrations of tested samples were determined and normalized to total protein content.

\section{TA Collection}

TA samples were obtained in the first 24 hours of life from intubated preterm infants born between 23 and 30 weeks' gestation. Samples were collected and processed as previously described. ${ }^{15,26}$ Briefly, endotracheal suctioning was sterilely performed and the aspirate was collected in a specimen trap. After centrifugation at $1000 \times g$ at $4^{\circ} \mathrm{C}$ for 5 minutes, the supernatant was separated, and samples were coded, aliquoted, and stored in a de-identified manner at $-80^{\circ} \mathrm{C}$ until later use. The protein content of each collected TA sample was measured using a bicinchoninic acid assay kit (Thermo Fisher Scientific). Clinical data documented for each study sample included the presence or absence of maternal chorioamnionitis, as confirmed by a placental pathologic examination performed as a part of standard clinical care.

\section{Preterm Human Lung Tissue Sections}

De-identified paraffin-embedded human lung sections were obtained from tissues collected at autopsy from preterm infants born between 26 and 32 weeks who died in the first 3 weeks after birth with a diagnosis of necrotizing enterocolitis, a condition associated with systemic inflammation (cases, $n=3$ ). Lung sections from gestational age-matched stillborn infants without histologic evidence of fetal lung inflammation or maternal history indicative of amniotic sac infections were also obtained (controls, $n=3$ ). Sections were immunostained for fibulin-5 or subjected to Hart's staining for elastic fibers.

\section{Statistical Analysis}

Comparisons between groups were performed using the $t$-test or a one-way analysis of variance followed by the Tukey post hoc test. All analyses were performed using Prism version 6.0 (GraphPad). $P<0.05$ was used for determining statistical significance.

\section{Results}

\section{Activation of Epithelial NF-кB Alters Saccular Stage Lung Development}

We used transgenic IKTA mice to generate NF- $\kappa \mathrm{B}-\mathrm{de}-$ pendent lung inflammation during discrete intervals of lung development. Figure $1 \mathrm{~A}$ illustrates the mating strategy used for obtaining IKTA mice and littermate controls. Pregnant dams were placed on Dox from embryonic days (E) 13 to 18 (pseudoglandular to canalicular stage) or from E13 to postnatal day (PN) 0 (pseudoglandular to midsaccular stage). In addition, to test the effect of transgene activation exclusively during the saccular stage, lactating dams were given Dox from PN0 to PN2. Although Dox administration from E13 to E18 did not cause any changes in airway branching or distal lung architecture in E18 IKTA lungs, dramatic dilation of distal lung structures, along with scattered areas of hemorrhage and airspace collapse/thickening, were evident in IKTA mice treated with Dox from E13 to PN0 and from PN0 to PN2 (Figure 1, B-G). Morphometric evaluation confirmed that airway branching was similar between IKTA and control mice (Figure $1 \mathrm{H}$ ) and quantified the degree of distal airspace dilation in saccular stage IKTA lungs (Figure 1I). Dilated terminal saccules in IKTA lungs were most prominent toward the periphery of the lung and could be identified visually as areas of lucency subjacent to the pleural surface in the lungs of postnatal mice (Figure 1, J and K). Saccular stage IKTA mice appeared cyanotic and were smaller than littermate controls (Figure 1, L-M). IKTA mice had impaired gas exchange, as evidenced by reduced oxygen saturation (Figure 1N). All IKTA pups treated with Dox from E13 to PN0 died within 24 hours 


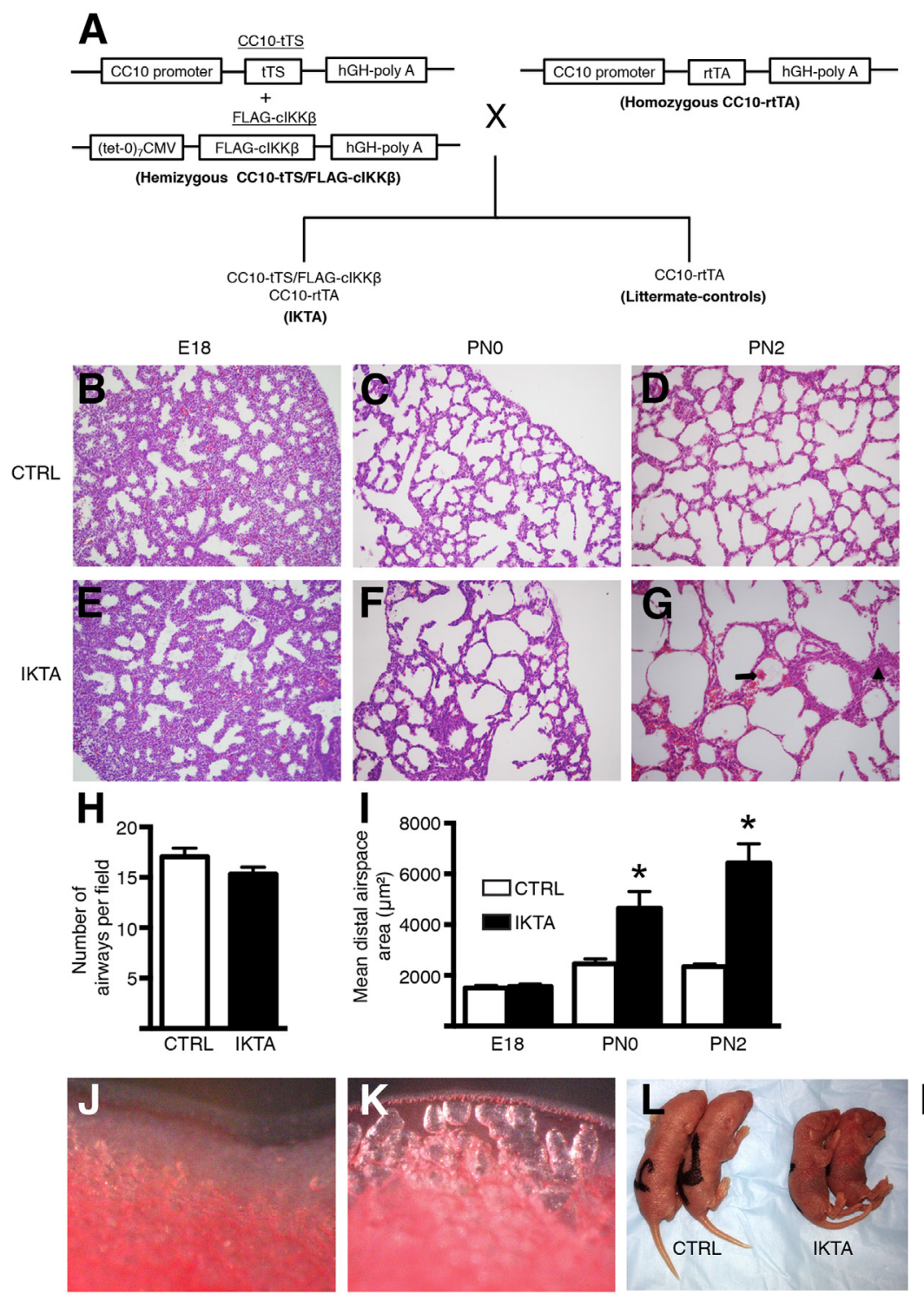

Figure 1 Airway epithelial NF- $\kappa$ B activation disrupts saccular stage lung development. Pregnant or lactating dams were treated with doxycycline in drinking water from embryonic days $(E) 13$ to 18 (denoted E18), E13 to postnatal day (PN) 0 (denoted PN0), or PN0 to PN2 (denoted PN2), after which lungs were harvested. A: Schematic illustration of the mating strategy for generating inhibitory $\kappa B$ kinase $\beta$ transactivated (IKTA) mice and littermate controls (CTRL). B-G: Representative hematoxylin and eosin-stained lung sections at E18 (B and E), PNO (C and F), and PN2 (D and G). Arrow denotes an area of hemorrhage; arrowhead denotes an area of airspace collapse in PN2 IKTA lungs (G). $\mathbf{H}$ and $\mathbf{I}$ : Morphometric evaluation of terminal airway counts at E18 (H) and mean distal airspace area in control and IKTA lungs at E18, PN0, and PN2 (I). J and K: Representative images showing distal PN2 control (J) and IKTA (K) lungs. L: Representative image showing control and IKTA pups from the same litter at PN2 (Dox PN0 to PN2). $\mathrm{M}$ and $\mathrm{N}$ : Body weight (M) and oxygen saturation (N) in PN2 IKTA and control pups. Data are expressed as means \pm SEM. $n=10$ to 15 lung fields per lung ( $\mathbf{H}$ and $\mathbf{I}$ ); $n=3$ to 4 pups per group ( $\mathbf{H}$ and $\mathbf{I}) ; n=10$ pups per group ( $\mathbf{M}$ and $\mathbf{N}$ ). ${ }^{*} P<0.05$. Original magnification, $\times 200$. CC10, Clara cell $10 \mathrm{kDa}$; CMV, cytomegalovirus; CIKK $\beta$, constitutively active I $\mathrm{B}$ kinase $\beta$; hGH, human growth hormone; tTS, tetracycline-controlled transcription silencer; rtTA, reverse tetracycline transactivator.
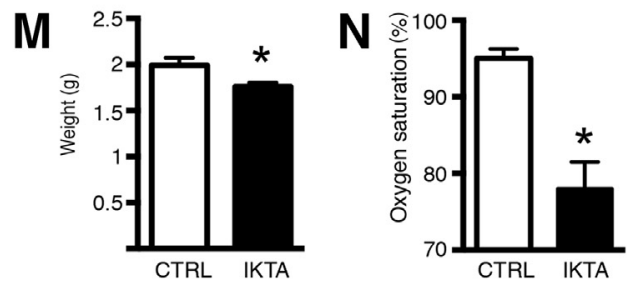

after birth, and IKTA pups treated with Dox from PNO to PN2 uniformly died by PN4. Other organs in IKTA mice appeared grossly normal, consistent with a prior study showing that transgene expression in this model is limited to the lungs. ${ }^{19}$

Because transgene activation limited to the canalicular stage (E18) did not appear to affect lung development, we verified that the FLAG-tagged cIKK $\beta$ transgene was similarly expressed during the canalicular and saccular stages. Immunostaining and Western blot assays detected similar transgene expression in E18 and PN2 IKTA lungs (Figure 2, A-G) with FLAG-tagged cIKK $\beta$ staining localized to the bronchiolar epithelium and scattered distal epithelial cells in IKTA lungs at both stages (Figure 2, B and E). Densitometry analysis of Western blots confirmed similar FLAG expression in E18 and PN2 IKTA lungs (Figure 2G). In addition, cell counts of FLAG-positive cells in the distal lung (excluding bronchiolar epithelial cells) also demonstrated a similar proportion of FLAG-positive cells around distal airspaces at both stages (means \pm SD: E18, $7.2 \% \pm 1 \%$; PN2, $8.8 \% \pm 1.2 \%$ ). In both E18 and PN2 IKTA lungs, we found increased mRNA expression of inflammatory cytokines (Figure 2, H and I) and an influx of inflammatory cells, predominantly neutrophils (Supplemental Figure S1). Together, these data indicate that airway epithelial NF- $\mathrm{BB}$ activation leads to inflammation during both the canalicular and saccular stages, but that lung development is selectively disrupted during the saccular stage.

\section{Epithelial-Derived Inflammation Disrupts Elastin Organization in Saccular Stage Lungs}

Because epithelial-driven inflammation in IKTA mice causes marked structural changes to lungs during the saccular stage, which is a time of rapid remodeling of the ECM 

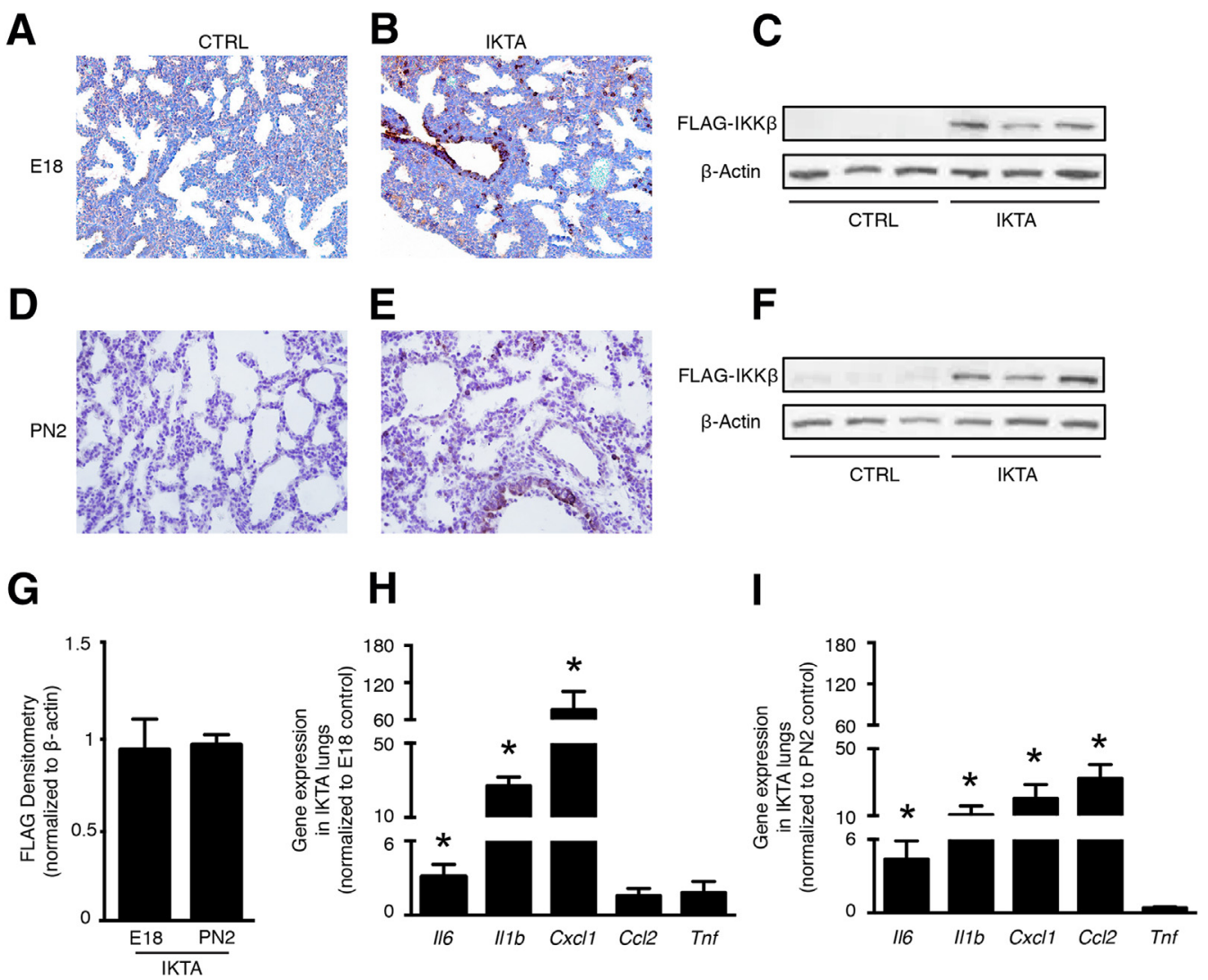

Figure 2 Conditional expression of the FLAG-tagged constitutively active IKB kinase $\beta$ (cIKK $\beta$ ) transgene results in inflammation during both the canalicular and saccular stage. Doxycycline in drinking water was provided to pregnant dams [embryonic days (E) 13 to 18] or lactating dams [postnatal days (PN) 0 to 2], after which lungs were collected. A-G: FLAG epitope expression in control (CTRL) and inhibitory $\kappa B$ kinase $\beta$ transactivated (IKTA) lungs at E18 $(\mathbf{A}-\mathbf{C})$ and PN2 (D-F) by immunohistochemistry and Western blot analysis. G: Densitometry of FLAG Western blots from E18 and PN2 IKTA lungs. H and I: Gene expression of select cytokines and chemokines in E18 (H) and PN2 (I) lungs measured by quantitative RT-PCR. Data are expressed as means \pm SEM. $n=4$ per group $(\mathbf{G}) ; n=6$ pups per group $(\mathbf{H}$ and $\mathbf{I})$. ${ }^{*} P<0.05$. Original magnification, $\times 400$.

compartment in the distal lung, we postulated that alterations in ECM composition or structure might contribute to lung dysfunction following the transition from in utero gas exchange to spontaneous breathing. As both collagen and elastin are critically important for structural integrity and tensile strength in the developing lung parenchyma, we investigated whether differences in these matrix proteins were apparent in saccular stage IKTA lungs. Immunostaining for collagens I and IV failed to show differences between PN2 control and IKTA lungs (Supplemental Figure S2, A and B). In addition, no quantitative changes in total lung collagen content were identified (Supplemental Figure S2C).

Elastin, a key component of the ECM, is produced and assembled around distal airspaces during the later stages of fetal lung development. ${ }^{27}$ Using Hart's elastin stain, we identified nascent strands of elastin fibers around the distal airspaces that appeared similar in IKTA and control lungs at E18; however, at PN0 and PN2, the organized meshwork of elastic fibers encircling the terminal saccules of control lungs was markedly abnormal in IKTA lungs (Figure 3, A-F). IKTA lungs at PN2 demonstrated a discontinuous and disorganized-appearing pattern of elastic fibers, which was confirmed by immunofluorescence and electron microscopy (Figure 3, G-J). Of note, elastin fiber assembly around developing blood vessels appeared normal in IKTA mice at PN2, indicating that abnormalities in elastin structures were limited to the distal lung parenchyma (Supplemental Figure S3). Despite differences in the appearance of elastin bundles, Western blot analysis for soluble elastin (Figure 3K) and quantitative image analysis of Hart's stained sections (Figure 3L) showed no differences in total elastin content between PN2 control and IKTA lungs. Together, these data show that epithelial-derived inflammation disrupts elastic fiber organization in the saccular stage lung parenchyma without a concurrent change in total lung elastin content.

\section{Critical Elastin Assembly Components Are Altered in Saccular Stage Lungs with Epithelial-Derived Inflammation}

We reasoned that the faulty elastin structure in saccular stage IKTA mice could have been due to either abnormal elastin assembly or increased elastin destruction. To investigate whether altered expression of important elastin 

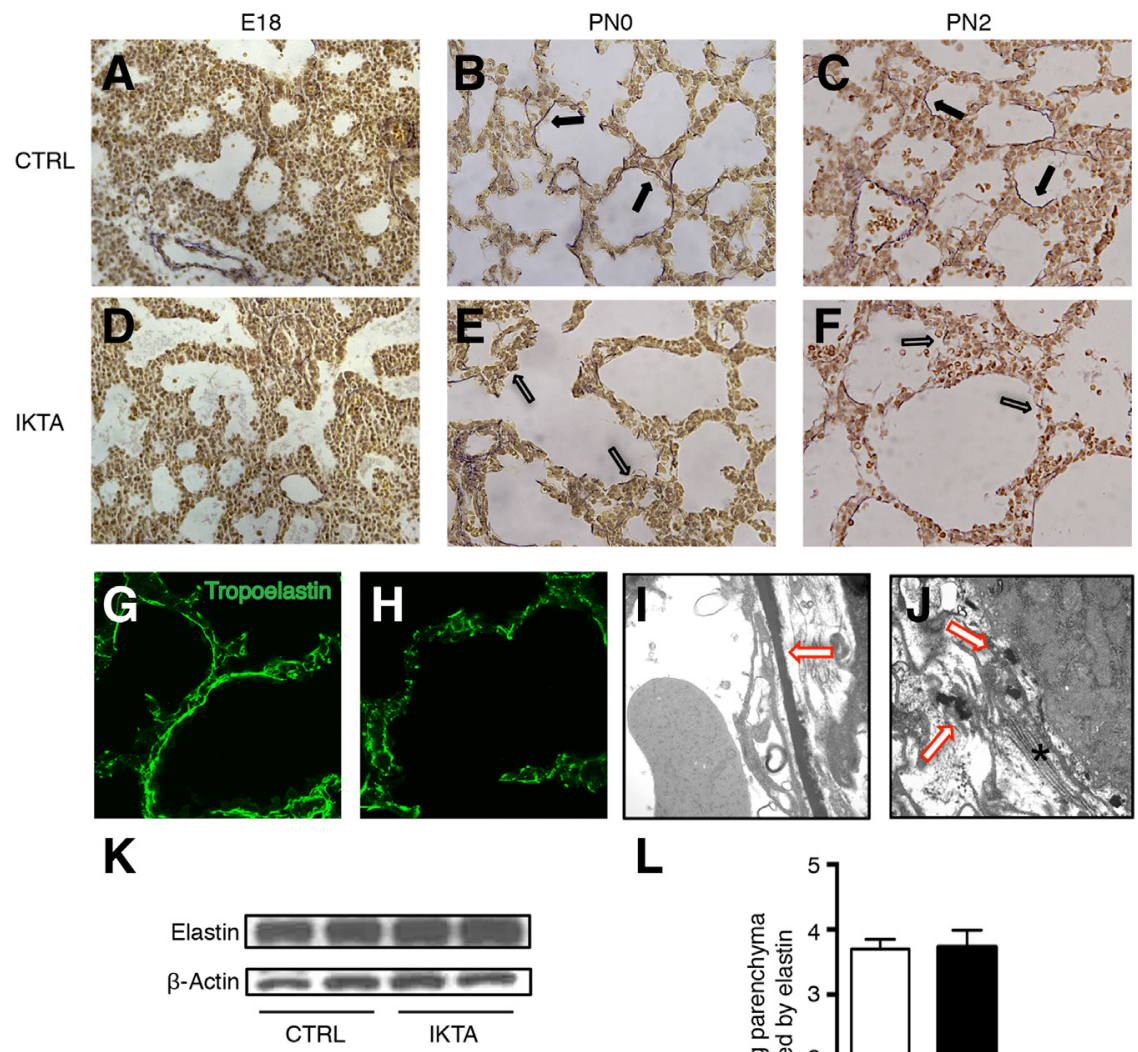

L

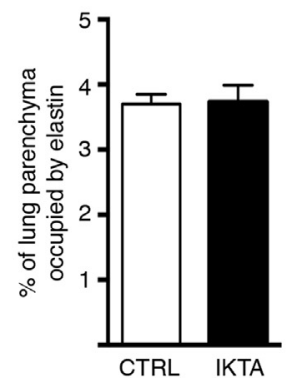

Figure 3 Elastic fiber organization is disrupted in saccular stage inhibitory $\kappa B$ kinase $\beta$ transactivated (IKTA) lungs. Pregnant or lactating dams were treated with doxycycline (Dox) in drinking water until lung harvest at embryonic day (E) 18 (Dox E13 to E18), postnatal day (PN) 0 (Dox E13 to PN0), or PN2 (Dox PN0 to PN2). A-F: Representative photomicrographs of Hart's elastin-stained lung sections from control (CTRL) (A-C) and IKTA (D-F) lungs. Closed arrows denote elastic fibers around terminal airspaces in controls at PNO (B) and PN2 (C). Open arrows denote fragmented elastic fibers in IKTA lungs at PNO (E) and PN2 IKTA (F). $\mathbf{G}$ and $\mathbf{H}$ : Tropoelastin immunostaining in PN2 control (G) and IKTA (H) lungs. I and J: Representative transmission electron microscopic images of PN2 control (I) and IKTA (J) lungs. Red arrows denote elastic fibers; asterisk denotes collagen bundles. K: Representative Western blot for soluble tropoelastin protein in lung tissue homogenates at PN2. L: Morphometric quantification of area occupied by insoluble elastin in PN2 control and IKTA lungs. Data are expressed as means \pm SEM. $n=10$ imaged fields for each of four separate control and IKTA lungs. Original magnification, $\times 400(\mathbf{A}-\mathbf{F}) ; \times 630(\mathbf{G}$ and $\mathbf{H})$; $\times 30,000$ (I and J). assembly components was involved in the distinct differences in elastic fiber organization in E18 and PN2 IKTA lungs, we quantified gene expression of critical elastin assembly components, including elastin (Eln); short fibulins (Fbln4 and Fbln5); members of the lysyl oxidase family of cross-linking enzymes, lysyl oxidase (Lox) and lysyl oxidase like-1 (Loxl1); and microfibrillar components fibrillins 1 and 2 (Fbn 1 and Fbn2). Expression of Eln, Fbln5, and Loxll were significantly greater in saccular stage lungs of control mice at PN2 compared to E18, indicating important developmental regulation of these elastin assembly components (Figure 4A). These developmental increases in the expression of Fbln 5 and Loxll were markedly attenuated in the saccular stage lungs of IKTA mice at PN2 (Figure 4A), implicating these genes as potentially important in dysregulated lung structure in saccular IKTA lungs. Expression of Fbln 4 and Fbnl were also inhibited in PN2 IKTA lungs compared to those in controls; however, mRNA for these genes were not significantly up-regulated in control lungs at PN2 compared to those at E18. Detailed investigation of the ontogeny of these elastin assembly components in the lungs of wild-type mice revealed increased levels of expression of Fbln5 and Loxll in the immediate postnatal period (Figure 4B). In contrast, expression of Fbln4 and Fbnl did not increase until PN5. Western blot analysis confirmed the up-regulation of fibulin-5 protein in the perinatal period from E18 to PN2, with decreased expression in PN2 IKTA lungs (Figure 4, C and D). Overall, these studies indicate that epithelial-driven inflammation prevents the normal developmental up-regulation of the critical elastin assembly components fibulin-5 and LoxL1 during the saccular stage.

To investigate whether destruction of elastic fibers might also contribute to the observed fragmented appearance of elastin, we measured elastase activity in PN2 IKTA lungs. Administration of Dox from PNO to PN2 did not increase total lung elastase activity in IKTA lungs compared to that in control lungs (Supplemental Figure S4A). In addition, we did not detect an increase in desmosine, a marker of elastin degradation, in lung homogenates from IKTA mice compared to that in littermate controls (Supplemental Figure S4B), suggesting that degradation of previously formed elastic fibers is not the primary mechanism of disrupted elastic fiber organization in saccular stage IKTA lungs.

\section{Inflammation Decreases Fibulin-5 Expression and Alters Elastic Fiber Assembly by Saccular Stage Lung Fibroblasts in Culture}

Fibroblasts are primarily involved in the production of elastin and its assembly components in the distal lung; 
A

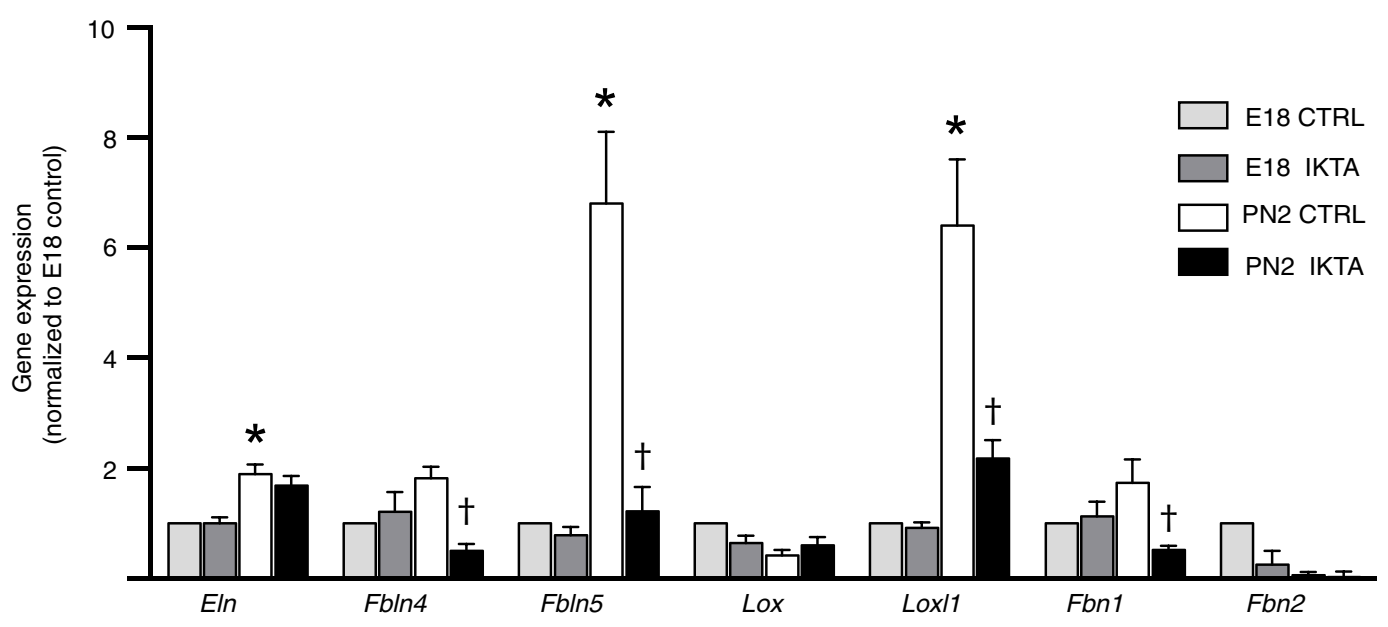

B
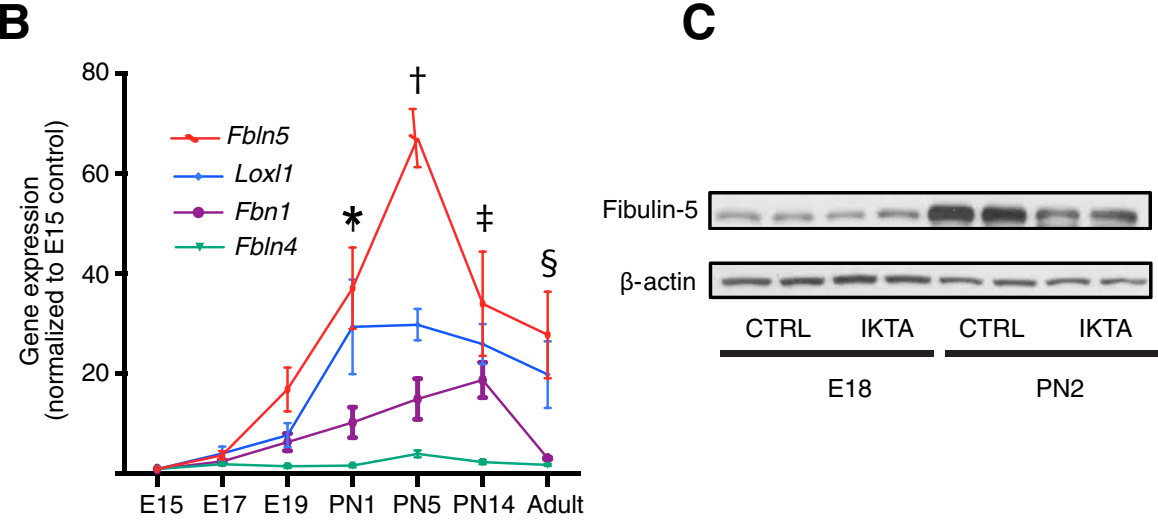

D

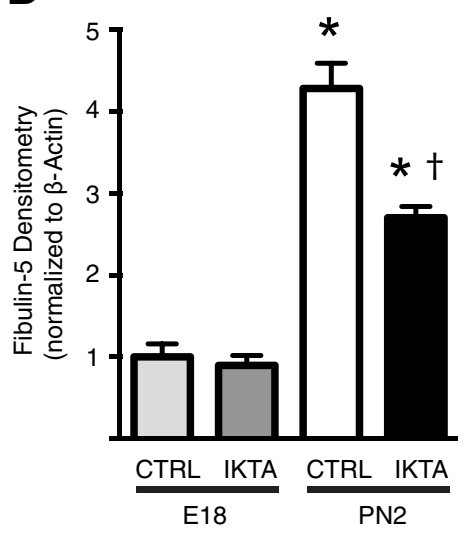

Figure 4 Critical elastic fiber assembly components are down-regulated in saccular stage inhibitory $\kappa$ B kinase $\beta$ transactivated (IKTA) lungs. A: Gene expression of critical elastin assembly components in embryonic day (E) 18 and postnatal day (PN) 2 control (CTRL) and IKTA lungs, as measured by quantitative RT-PCR. B: Ontogeny of expression of Fbln4, Fbln5, Loxl1, and Fbn1 during lung development in wild-type mice. C and D: Western blot analysis of lung tissue homogenates for fibulin-5 protein in E18 and PN2 lungs. Representative Western blot images (C) and densitometry analysis (D). Data are expressed as means \pm SEM. $n=4$ per group. ${ }^{\star} P<0.05$ versus E18 controls (A), for expression of Fbln5 and Loxl1 at PN1 versus expression at E15 (B), and for fibulin-5 protein expression versus expression in E18 control lungs (C and $\mathbf{D}){ }^{\dagger}{ }^{\dagger} P<0.05$ versus PN2 controls $(\mathbf{A})$, for expression of all four genes at PN5 versus expression at E15 (B), and for fibulin-5 protein expression versus expression in PN2 control lungs (C and $\mathbf{D}) ;{ }^{\ddagger} P<0.05$ for expression of Fbln5, Loxl1, and Fbn1 at PN14 versus expression at E15 (B); and ${ }^{\S} P<0.05$ for expression of Fbln5 in adult lungs versus expression at E15 (B).

therefore, we postulated that soluble inflammatory mediators produced by the airway epithelium in IKTA mice might activate inflammatory signaling in the lung mesenchyme and suppress the expression of these factors in fibroblasts. Therefore, we performed fluorescent immunostaining for an activated form of the transcription factor p65 (RelA) component of NF- $\kappa \mathrm{B}$ (phosphoserine 276) ${ }^{28,29}$ in the lungs of IKTA and control mice. We found a marked increase in immunostaining of phospho-p65 in mesenchymal cells in IKTA lungs compared to that in control lungs (Figure 5A), suggesting that activation of NF- $\kappa \mathrm{B}$ in the airway epithelium can initiate a wave of NF- $\kappa \mathrm{B}$ activation in other cell types, including fibroblasts in the lung mesenchyme.

Next, we tested whether bronchoalveolar lavage fluid from IKTA mice could activate NF- $\kappa \mathrm{B}$ and inhibit elastin assembly component expression in primary lung fibroblasts from PN2 mice. For these studies, we isolated lung fibroblasts from PN2 NF- $\mathrm{B}-\mathrm{GFP}-$ luciferase mice, a reporter mouse strain for NF- $\kappa \mathrm{B}$ activation, and cultured these cells in the presence of bronchoalveolar lavage fluid from IKTA and control mice. We found that bronchoalveolar lavage fluid from IKTA mice reduced the expression of fibulin-5 (Figure 5B) and activated the NF- $\mathrm{KB}$ pathway (Figure 5C); however, no differences in the levels of expression of Loxl1, Fbln4, or Fbn1 were identified (Figure 5B).

Based on these findings, we tested whether NF- $\kappa \mathrm{B}$ activation in saccular stage fibroblasts could be involved in the down-regulation of fibulin-5 expression by saccular stage lung fibroblasts. We treated cells with $E$. coli LPS, which activates NF- $\kappa$ B through Toll-like receptor 4. Consistent with other studies, LPS activated the NF- $\kappa$ B pathway 

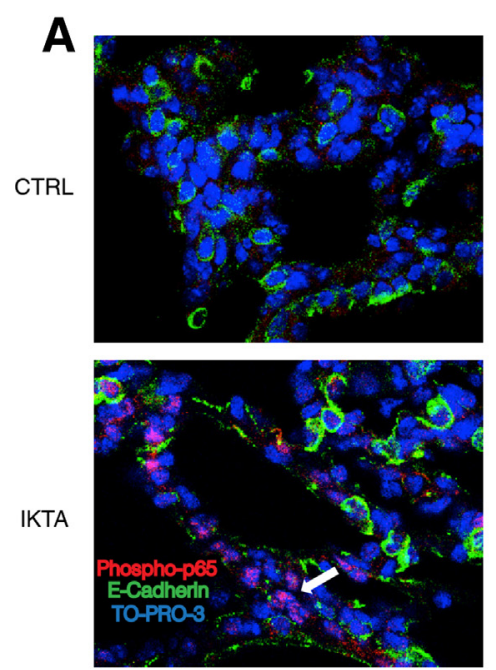

D

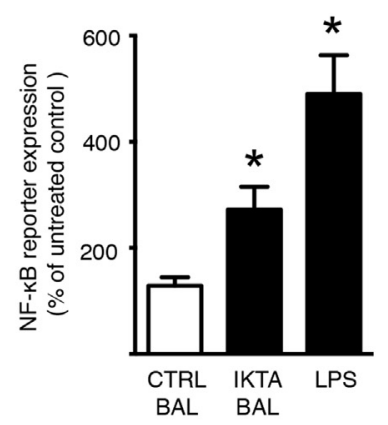

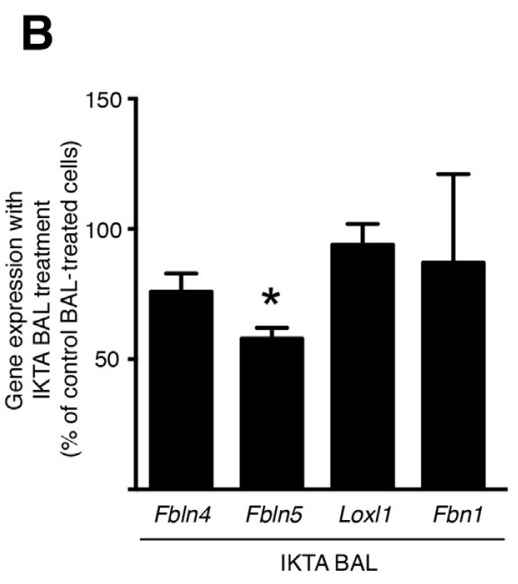
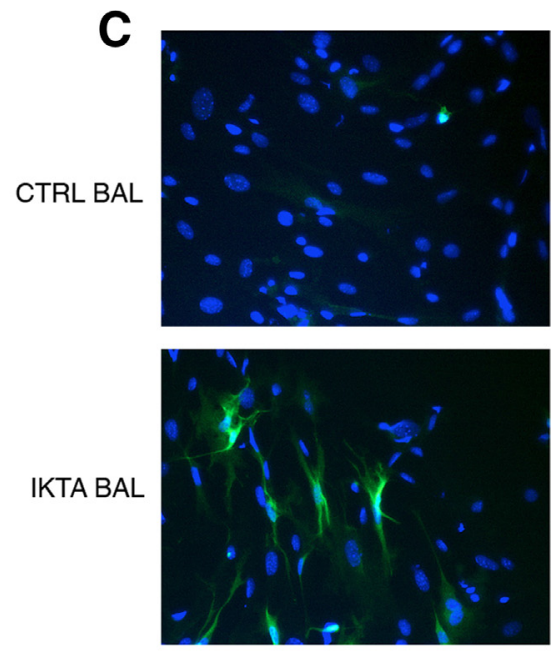

E

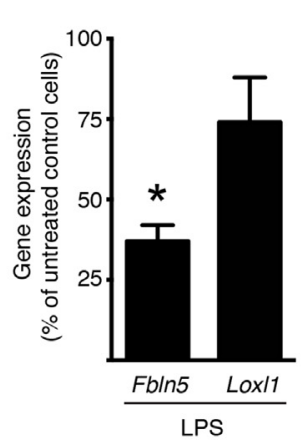

$\mathbf{F}$

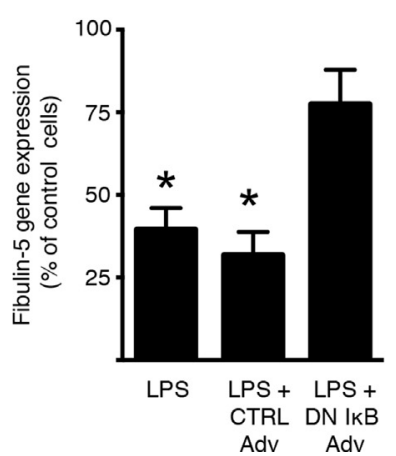

Figure 5 Epithelial inflammation in inhibitory $\kappa B$ kinase $\beta$ transactivated (IKTA) lungs results in NF- $\kappa$ B activation and decreased fibulin-5 expression by interstitial fibroblasts. A: Representative images of control (CTRL) and IKTA lung at postnatal day (PN) 2 immunostained for phosphoserine 276 in the transcription factor p65 (RelA) component of NF- $\kappa$ B as a marker of NF- $\kappa B$ activation. Arrow denotes cells in the interstitium with phospho-p65 staining. B and C: Lung fibroblasts were isolated from PN2 NF- $\mathrm{BB}-\mathrm{GFP}$-luciferase (NGL) mice and cultured in the presence of bronchoalveolar lavage (BAL) fluid from adult control or IKTA mice that were treated with doxycycline in drinking water $(1 \mathrm{~g} / \mathrm{L})$ for 7 days $(50 \mu \mathrm{L}$ of BAL per $500 \mu \mathrm{L}$ of culture medium). B: Gene expression of elastin assembly components in cells treated with control or IKTA BAL. C: Representative immunostaining for green fluorescent protein as an indicator of NF- $K B$ activation in NGL fibroblasts treated with control or IKTA BAL. D and E: PN2 NGL fibroblasts were treated with IKTA BAL or lipopolysaccharide (LPS) (800 $\mathrm{ng} / \mathrm{mL}$ ). Luciferase expression (D) was quantified as a measure of NF- $\kappa B$ activation and gene expression of select elastin assembly components (E) was assessed using quantitative RT-PCR (RT-qPCR). F: Adenoviral vectors expressing a dominant negative IKB- $\alpha$ (DN IKB Adv) or control (Cre recombinase; CTRL Adv) (1500 multiplicity of infection) were added to PN2 NGL fibroblasts treated with $800 \mathrm{ng} / \mathrm{mL}$ of Escherichia coli LPS for 24 hours, and Fbln5 expression was then quantified by RT-qPCR. Data are expressed as means \pm SEM. $n=4$ per group. ${ }^{*} P<0.05$ versus control BAL-treated cells (B), versus untreated control cells (E and F). Original magnification, $\times 200$ (C); $\times 400$ (A). T0-PRO-3, Life Science Technologies (Grand Island, NY).

(Figure 5D) and reduced the expression of Fbln5 in PN2 NF- $\kappa \mathrm{B}-\mathrm{GFP}-$ luciferase lung fibroblasts. Although the expression of Loxll also trended to be lower with LPS treatment, this did not reach statistical significance (Figure 5E). Overexpression of a dominant inhibitor of the $\mathrm{NF}-\kappa \mathrm{B}$ pathway in PN2 fibroblasts, using an adenoviral vector, restored fibulin-5 expression after LPS treatment (Figure 5F). These results support the idea that the propagation of NF- $\kappa \mathrm{B}$ activity from epithelial cells to fibroblasts in saccular stage IKTA mice regulates the expression of elastin assembly components.

Because we found that fibulin-5 was highly expressed in saccular stage lungs, and that its expression was consistently down-regulated by inflammatory stimuli, we investigated whether fibulin-5 provides critical regulation for elastic assembly by saccular stage lung fibroblasts. For these studies, we cultured saccular stage lung fibroblasts with LPS or vehicle for 48 hours and evaluated extracellular elastin fiber assembly. In control (vehicle-treated) cells, both fibulin-5 and elastin were organized as a dense reticular network in the extracellular space (Figure 6, A and B). In contrast, minimal immunostaining of fibulin-5 was detected in LPStreated cells (Figure 6C), and elastic fiber network formation was markedly reduced (Figure 6D). We then tested whether adenoviral delivery of $F b \ln 5$ or exogenous recombinant fibulin-5 protein could rescue elastin network formation in LPS-exposed cells. Efficient transfection of lung fibroblasts was confirmed in initial experiments using adenovirus-encoding GFP (Supplemental Figure S5). When Fbln 5 was overexpressed using an adenoviral vector in LPS-treated cells, we observed partial restoration of the extracellular elastin network (Figure 6, E and F). The 

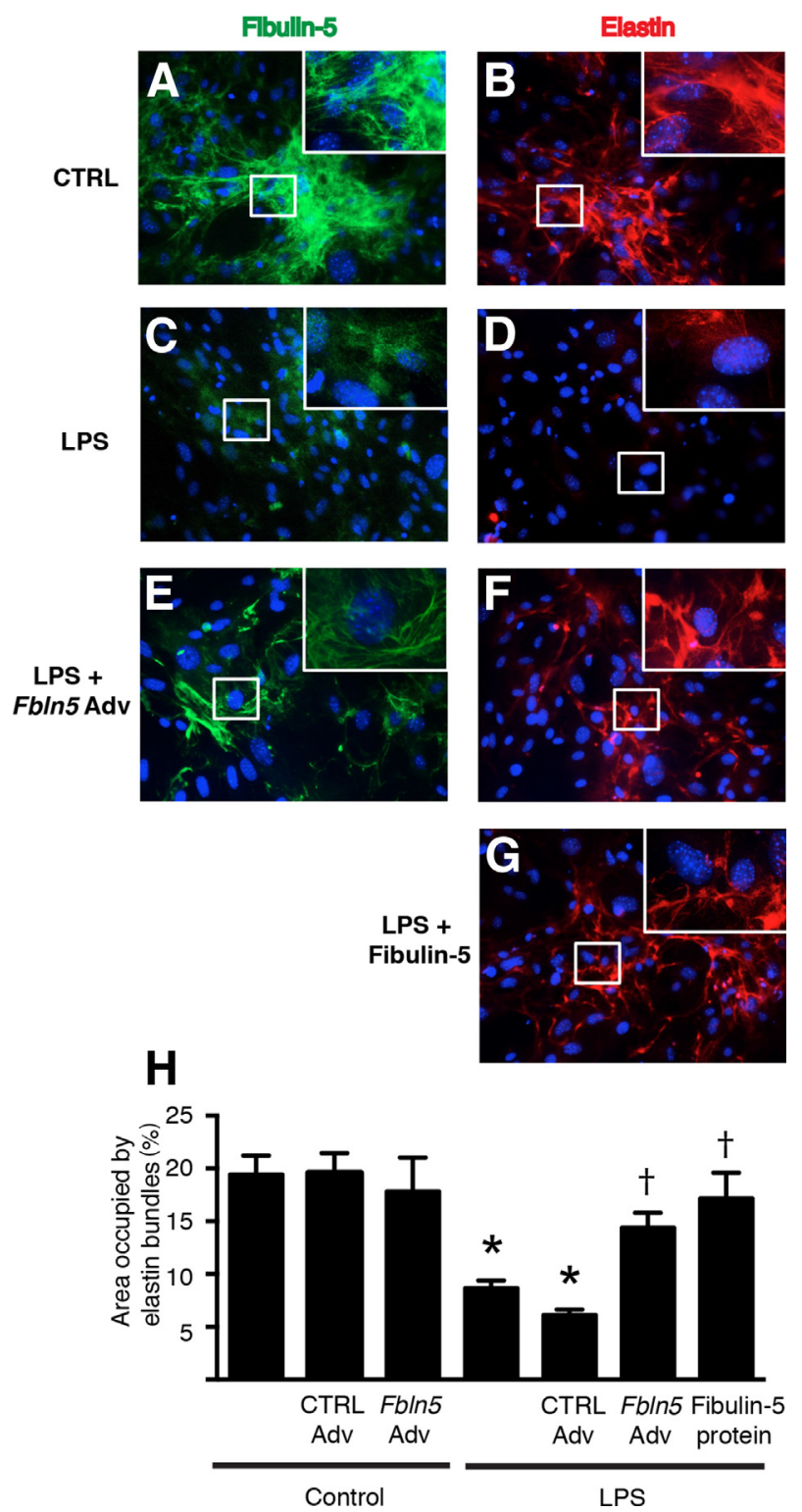

Figure 6 Inflammation reduces fibulin-5 expression and disrupts elastic fiber assembly by saccular stage lung fibroblasts. Postnatal day (PN) $2 \mathrm{NF}-\mathrm{KB}-\mathrm{GFP}$-luciferase fibroblasts were grown to confluence and cultured with or without $800 \mathrm{ng} / \mathrm{mL}$ of lipopolysaccharide (LPS) for 48 hours. In some experiments, LPS-treated cells were treated with adenoviral fibulin- 5 (Fbln5 Adv), control adenovirus expressing Cre recombinase (CTRL Adv), or recombinant fibulin-5 protein. $\mathbf{A}-\mathbf{G}$ : Representative immunostaining for fibulin-5 (A, C, and E), and elastin (B, D, F, and $\mathbf{G})$ in PN2 NGL fibroblasts. The boxed areas correspond to the insets at higher magnification. $\mathbf{H}$ : Quantification of the area occupied by elastin in immunostained images. Data are expressed as means \pm SEM. $n=15$ to 20 random microscopic fields per group from two separate experiments. ${ }^{*} P<0.05$ versus untreated control cells; ${ }^{\dagger} P<0.05$ versus LPS-treated cells. Original magnification, $\times 200$ (main images); $\times 600$ (insets).

addition of recombinant fibulin-5 to the cell culture medium also resulted in a rescue of the elastin network in LPStreated cells (Figure 6, G and $\mathrm{H}$ ). Collectively, these data indicate that fibulin-5 is important for proper extracellular assembly of elastic fibers produced by saccular stage lung fibroblasts.
Inflammatory Mediators Down-Regulate Fibulin-5 Expression and Disrupt Elastic Fiber Assembly in Preterm Human Lungs

Because we observed decreased fibulin-5 expression and altered elastin organization by saccular mouse lung fibroblasts exposed to inflammatory stimuli, we investigated whether epithelial lining fluid from inflamed preterm human lungs could also disrupt elastin assembly by saccular stage lung fibroblasts. For these experiments, day of life 1 TAs were collected from preterm infants with or without exposure to histopathologically confirmed maternal chorioamnionitis. The addition of TA from neonates exposed to chorioamnionitis to the culture medium of saccular stage mouse lung fibroblasts, but not TA from control subjects, resulted in reduced Fbln5 expression and impaired extracellular elastin network formation (Figure 7, A and B). This reduced-elastin network was reversed by Fbln5 overexpression (Figure 7, B and C).

Next, we examined whether inflammation in saccular stage human lungs was associated with reduced fibulin-5 and abnormal organization of elastic fibers. We obtained saccular stage autopsy lung sections from stillborn infants (controls; $n=3$ ) and from preterm infants with systemic inflammation as a result of necrotizing enterocolitis (cases; $n=3$ ). Immunoreactive fibulin-5 was seen outlining the distal airspaces in lung sections from controls, but reduced fibulin-5 expression was detectable around the terminal saccules in the lung sections from preterm infants exposed to inflammatory stimuli (Figure 7D). Although the elastic fibers in control lungs were arranged circumferentially around the terminal airspaces, they were discontinuous and demonstrated a frayed appearance in the saccular stage lungs of the preterm infants with systemic inflammation (Figure 7D). Taken together, these data indicate that exposure to inflammation during the saccular stage alters elastin organization and disrupts the ECM scaffold in the developing lung mesenchyme.

\section{Discussion}

These studies identify a critical window for elastin assembly in the lung parenchyma during the saccular stage of lung development. During this period, epithelial-driven inflammation impairs developmentally specified up-regulation of elastin assembly components, particularly fibulin-5, resulting in a dysfunctional elastin network that severely disrupts the structure and function of the developing saccular stage lung. Expression of the elastin assembly protein fibulin-5 by saccular stage lung fibroblasts can be inhibited by proinflammatory stimuli that activate the NF- $\kappa$ B pathway, suggesting that a network of inflammatory signaling initiated by the epithelium is involved in disrupting elastic fiber assembly.

Several lines of evidence support a nonredundant role for elastin in maintaining structural integrity in the saccular 
A

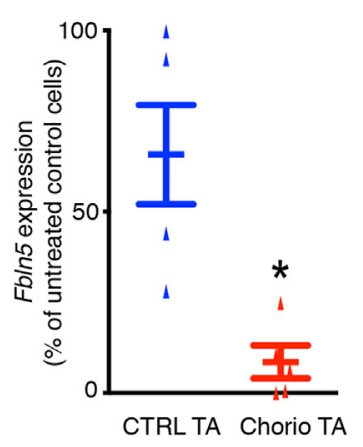

B

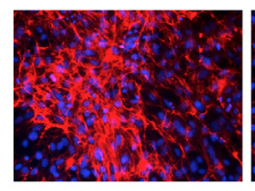

CTRL TA

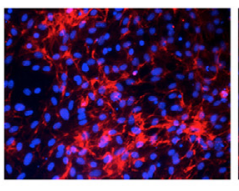

Chorio TA

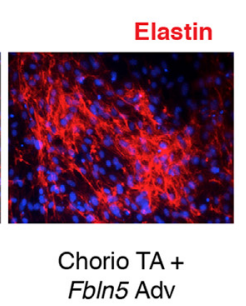

Fbln5 Adv
C

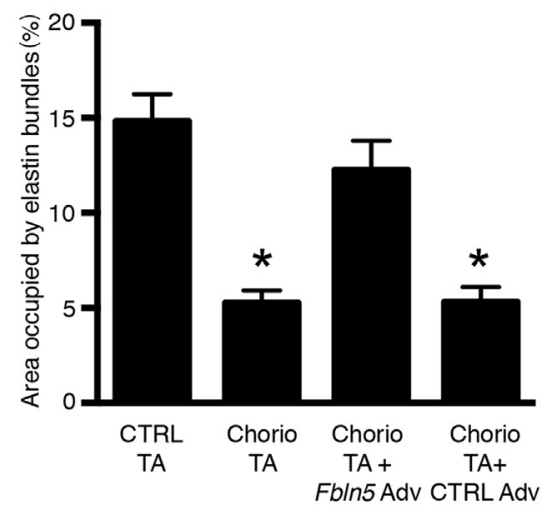

D

Fibulin-5

Elastin

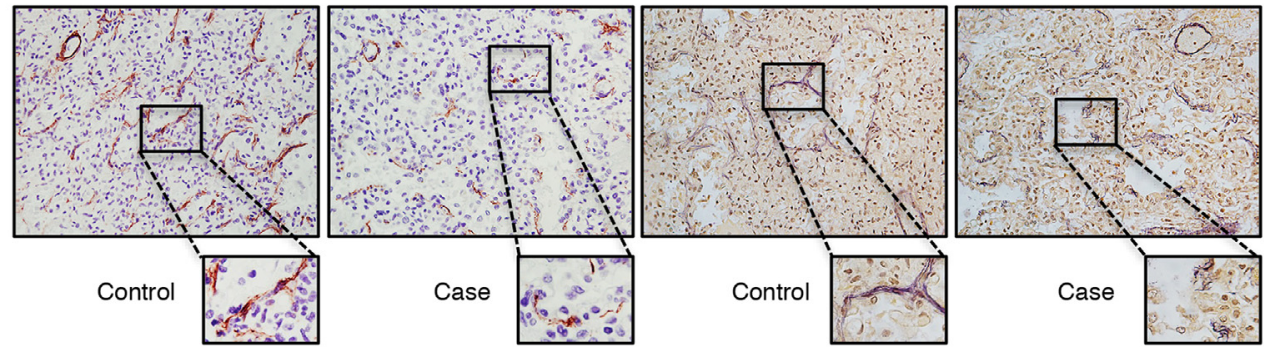

Figure 7 Inflammation in the saccular stage human lung down-regulates fibulin-5 expression and alters elastic fiber organization. A-C: Postnatal day (PN) $2 \mathrm{NF}-\mathrm{KB}$-GFP-luciferase (NGL) lung fibroblasts were cultured for 48 hours in serum-free conditions in the presence of tracheal aspirates (TA) from preterm infants with or without exposure to chorioamnionitis. A: Expression of Fbln5 in mouse lung fibroblasts treated with TAs from infants exposed to antenatal inflammation (Chorio TA) compared to control infant TA (CTRL TA). B: Representative immunostaining of elastin in NGL fibroblasts treated with CTRL or Chorio TA and Chorio TA with the addition of adenoviral vector expressing fibulin-5. C: Quantification of the area occupied by the elastin network in immunostained images. Fibroblasts treated with Chorio TA with the addition of adenoviral vector expressing Cre recombinase (CTRL Adv) were also included as controls in these experiments. D: Autopsy lung sections were collected from age-matched stillborn infants (control) or infants exposed to early systemic inflammation because of necrotizing enterocolitis (case) and immunostained for fibulin-5 or stained with Hart's stain for elastic fibers. Images shown are representative photomicrographs of lung sections from a stillborn control and an infant exposed to early systemic inflammation immunostained for fibulin-5 or stained with Hart's stain for elastic fibers. The boxed areas correspond to the images at higher magnification. Data are expressed as means \pm SEM. $n=5$ per group (A); $n=15$ to 20 microscopic fields per group (C). ${ }^{*} P<0.05$ (A), versus CTRL TA treatment (C). Original magnification, $\times 200(\mathbf{B}) ; \times 400($ D, main images); $\times 600(\mathbf{D})$.

stage. Elastin-knockout mice develop fewer dilated distal airspaces in the saccular stage, suggesting roles for elastin in terminal airway branching and/or providing structural support to developing saccules. ${ }^{30}$ In addition, mice deficient in lysyl oxidase, a collagen and elastin cross-linking enzyme, demonstrate fragmented elastic fibers and disrupted saccular lung development. ${ }^{31}$ Our results indicate that elastin organization around developing terminal airspaces is critically important in maintaining the structural framework in developing saccular stage lungs. This function is clearly different from the well-established role of elastin organization at septal tips, an essential prerequisite for normal secondary septation and alveolarization. ${ }^{32,33}$ Thus, it appears that perturbations in the elastin assembly process can affect lung development in both the saccular and alveolar stages of lung development.

Our findings are distinct from the increased, yet disorganized, distribution of elastin observed in the lungs of human infants with established bronchopulmonary dysplasia ${ }^{34,35}$ or that seen in neonatal lung injury models in which animals undergo prolonged exposure to mechanical ventilation or hyperoxia during the late saccular and alveolar stages of development. ${ }^{36-38}$ It is likely that in these settings, increased production of elastin occurs as a compensatory mechanism to persistent injury/inflammation. However, it is unclear whether this response results in a functional improvement in elastin organization in the distal lung. In emphysema, where the mature elastin scaffold is disrupted, a similar compensatory increase in the production of elastin occurs, ${ }^{39,40}$ but developmental programs required for correct assembly of elastic fibers are not activated, and structural integrity of the lung remains impaired. ${ }^{41}$

Fibulin-5 is an important adaptor molecule in the elastin assembly process. Along with tropoelastin, which forms the amorphous core in elastic fibers, the short fibulins, fibulin 4 and 5, are components critical for the assembly of ECM components. ${ }^{42,43}$ Although both fibulins have distinct noncompensable roles during elastic fiber formation, fibulin-5 is expressed at greater levels in the lung. ${ }^{42}$ In addition, although fibulin-4 is important for both elastin and collagen organization, fibulin-5 functions specifically in elastin assembly. ${ }^{42}$ Consistent with findings from a previous report, ${ }^{44}$ we 
observed that fibulin-5 expression is developmentally regulated in the lung, with a distinct peak in expression during the saccular stage, coincident with the period of early organization of elastic fibers in the lung.

Mutations in FBLN5 in humans result in autosomal recessive cutis laxa, a condition characterized by childhoodonset pulmonary emphysema. ${ }^{45}$ Isolated deletion of $\mathrm{Fbln} 5$ in mice does not result in a profound neonatal lung phenotype but rather in progressive emphysema with age, ${ }^{46,47}$ and in saccular stage Fbln $5^{-1-}$ mice, thin strands of elastic fibers can assemble around terminal airspaces, albeit to a lesser extent compared to those in wild-type control lungs. ${ }^{48}$ This finding suggests some redundancy in fibulin-5 function with other elastin assembly components during normal development. Indeed, in Fbln5-deficient mouse lungs, the assembly of elastin may occur by an alternate pathway using fibulin- $4{ }^{48}$ Along with $F b \ln 5$, we found reduced levels of expression of Fbln4, Loxll, and Fbnl in saccular stage IKTA mouse lungs, potentially explaining the more severe neonatal phenotype seen in IKTA mice compared to that in mice with Fbln5 deficiency. Yet, our finding that the restoration of fibulin-5 expression alone resulted in a significant enhancement in elastic fiber organization by fibroblasts treated with LPS or TA from infants exposed to antenatal inflammation suggests that fibulin-5 is a critical determinant of elastin organization in the setting of inflammation. These findings indicate that restoration of fibulin-5 activity could be a therapeutic target for preventing early lung structural changes resulting from perinatal inflammation.

Available data suggest that NF- $\kappa \mathrm{B}$ activation can have variable effects on the lung, depending on cellular context, the specific component(s) of the NF- $\kappa \mathrm{B}$ pathway that are activated, and the developmental stage. ${ }^{49}$ In adult mice, high-level transgene expression in IKTA mice causes pathology consistent with the acute respiratory distress syndrome, resulting in a high mortality during the first 2 weeks of Dox treatment. ${ }^{19}$ In contrast, prolonged treatment with lower-dose Dox results in emphysema with evidence of interalveolar septum destruction and elastin degradation after 4 to 6 months of persistent inflammation. ${ }^{50}$ During saccular stage lung development, IKK $\beta$-driven activation of $\mathrm{NF}-\kappa \mathrm{B}$ in the airway epithelium results in robust neutrophilic inflammation, elastin fragmentation, and perinatal mortality. Although these studies suggest that altered elastin structure occurs in both neonatal and adult IKTA lungs, it appears that altered elastin assembly plays a less important role than does elastin degradation in adult IKTA lungs, likely because elastin assembly occurs primarily during the perinatal period, with little expression of elastin assembly components in the adult lung. Although we measured elastase activity in whole lungs from embryonic and neonatal IKTA mice, technical limitations prevented assessment in subcompartments of the lung. Thus, our results do not rule out the possibility of localized areas of increased elastase activity resulting from neutrophilic inflammation, which could also contribute to the disorganization of elastic fibers in perinatal IKTA mice.

In contrast to the findings from our studies, Londhe et $\mathrm{al}^{51}$ showed that RelA overexpression under control of the surfactant protein $\mathrm{C}$ promoter in the alveolar epithelium results in accelerated lung maturity, with no evidence of lung inflammation. Although not specifically examined by these investigators, it may be that the profile of NF- $\kappa \mathrm{B}-$ dependent mediators produced in this model is substantially different from that in IKTA mice. Also, because recruited inflammatory cells may be involved in mediating the epithelial cell-to-mesenchymal cell crosstalk in IKTA lungs that represses elastin assembly, the lack of inflammatory cell recruitment from RelA overexpression may explain the differential phenotypes observed in these two models.

In addition to epithelial NF- $\kappa \mathrm{B}$ activation, we found evidence of NF- $\kappa \mathrm{B}$ activation in mesenchymal cells in IKTA mice, suggesting that a wave of NF- $\kappa \mathrm{B}$ activation mediates the parenchymal abnormalities in IKTA lungs. From this perspective, the absence of an airway branching phenotype during the canalicular stage in IKTA mice is somewhat surprising, particularly because we have previously shown that activation of NF- $\kappa \mathrm{B}$ signaling in mesenchymal cells during the canalicular stage reduces expression of fibroblast growth factor 10, which is important for branching morphogenesis. ${ }^{17}$ IKTA mice treated with Dox during the canalicular stage from E13 to E18 had normal proximal and distal lung structures at E18; however, after delivery at PN0, these mice were cyanotic and died in the immediate postnatal period (data not shown). Although this phenotype may simply reflect continued inflammation after withdrawal of Dox, it is possible that inflammatory changes during the canalicular stage are sufficient for priming the saccular stage lung to disrupted lung function after birth. Future studies may shed light on these issues by addressing whether the observed phenotype during saccular stage lung development results from direct effects of inflammatory mediators produced by the epithelium or indirect effects of mediators produced by activated and/or recruited inflammatory cells. Differences in inflammatory mediators produced by epithelial cells or inflammatory cells during the canalicular and saccular stages could determine whether the NF- $\kappa \mathrm{B}$ signal is propagated to fibroblasts. Relevant to this point, transgenic expression of $I l l b$ in the mouse airway epithelium during the saccular stage has been shown to alter lung development. ${ }^{52}$ As NF- $\mathrm{KB}$ drives the transcription of multiple pro-inflammatory genes, the cumulative effects of these factors may explain why lung abnormalities in our model are more severe than with conditional $I l l b$ expression alone; however, the findings from this study supports the idea that the saccular stage is particularly vulnerable to the effects of epithelial-derived inflammation.

In summary, here we have demonstrated that activating innate immune pathways in the airway epithelium disrupts elastic fiber organization and alters saccular stage lung development. We propose that interventions to restore 
down-regulated components of elastin assembly could prove beneficial in supporting normal lung development in premature infants.

\section{Acknowledgments}

We thank Amy Billings, Theresa Rogers, Steven Steele, Pete Gulleman, and Jennifer Herrington for their assistance with the experiments. We also thank our colleagues Drs. Susan Guttentag, Scott Baldwin, and Roy Zent for their helpful suggestions and comments. Anti-fibulin-5 antibody and adenovirus encoding fibulin-5 or GFP were generous gifts from Dr. Hiromi Yanagisawa. Female mice expressing rtTA under control of the CC1O promoter were a gift from Dr. Jeffrey Whitsett.

\section{Supplemental Data}

Supplemental material for this article can be found at http://dx.doi.org/10.1016/j.ajpath.2016.02.016.

\section{References}

1. Morrisey EE, Hogan BL: Preparing for the first breath: genetic and cellular mechanisms in lung development. Dev Cell 2010, 18:8-23

2. Ribatti D, Santoiemma M: Epithelial-mesenchymal interactions: a fundamental Developmental Biology mechanism. Int J Dev Biol 2014, 58:303-306

3. Hogan BL, Yingling JM: Epithelial/mesenchymal interactions and branching morphogenesis of the lung. Curr Opin Genet Dev 1998, 8: 481-486

4. Warburton D, El-Hashash A, Carraro G, Tiozzo C, Sala F, Rogers O, De Langhe S, Kemp PJ, Riccardi D, Torday J, Bellusci S, Shi W, Lubkin SR, Jesudason E: Lung organogenesis. Curr Top Dev Biol 2010, 90:73-158

5. Warburton D, Schwarz M, Tefft D, Flores-Delgado G, Anderson KD, Cardoso WV: The molecular basis of lung morphogenesis. Mech Dev 2000, 92:55-81

6. Kramer BW, Kallapur S, Newnham J, Jobe AH: Prenatal inflammation and lung development. Semin Fetal Neonatal Med 2009, 14:2-7

7. Goldenberg RL, Hauth JC, Andrews WW: Intrauterine infection and preterm delivery. N Engl J Med 2000, 342:1500-1507

8. Mueller-Heubach E, Rubinstein DN, Schwarz SS: Histologic chorioamnionitis and preterm delivery in different patient populations. Obstet Gynecol 1990, 75:622-626

9. Galinsky R, Polglase GR, Hooper SB, Black MJ, Moss TJ: The consequences of chorioamnionitis: preterm birth and effects on development. J Pregnancy 2013, 2013:412831

10. Jobe AH: Effects of chorioamnionitis on the fetal lung. Clin Perinatol 2012, 39:441-457

11. Prince LS, Dieperink HI, Okoh VO, Fierro-Perez GA, Lallone RL: Toll-like receptor signaling inhibits structural development of the distal fetal mouse lung. Dev Dyn 2005, 233:553-561

12. Schleimer RP, Kato A, Kern R, Kuperman D, Avila PC: Epithelium: at the interface of innate and adaptive immune responses. J Allergy Clin Immunol 2007, 120:1279-1284

13. Sha Q, Truong-Tran AQ, Plitt JR, Beck LA, Schleimer RP: Activation of airway epithelial cells by toll-like receptor agonists. Am J Respir Cell Mol Biol 2004, 31:358-364

14. Christman JW, Sadikot RT, Blackwell TS: The role of nuclear factorkappa B in pulmonary diseases. Chest 2000, 117:1482-1487
15. Benjamin JT, Carver BJ, Plosa EJ, Yamamoto Y, Miller JD, Liu JH, van der Meer R, Blackwell TS, Prince LS: NF-kappaB activation limits airway branching through inhibition of Sp1-mediated fibroblast growth factor-10 expression. J Immunol 2010, 185:4896-4903

16. Blackwell TS, Hipps AN, Yamamoto Y, Han W, Barham WJ, Ostrowski MC, Yull FE, Prince LS: NF-kappaB signaling in fetal lung macrophages disrupts airway morphogenesis. J Immunol 2011, $187: 2740-2747$

17. Benjamin JT, Smith RJ, Halloran BA, Day TJ, Kelly DR, Prince LS FGF-10 is decreased in bronchopulmonary dysplasia and suppressed by Toll-like receptor activation. Am J Physiol Lung Cell Mol Physiol 2007, 292:L550-L558

18. Iosef C, Alastalo TP, Hou Y, Chen C, Adams ES, Lyu SC, Cornfield DN, Alvira CM: Inhibiting NF-kappaB in the developing lung disrupts angiogenesis and alveolarization. Am J Physiol Lung Cell Mol Physiol 2012, 302:L1023-L1036

19. Cheng DS, Han W, Chen SM, Sherrill TP, Chont M, Park GY, Sheller JR, Polosukhin VV, Christman JW, Yull FE, Blackwell TS: Airway Epithelium Controls Lung Inflammation and Injury through the NF- B Pathway. J Immunol 2007, 178:6504-6513

20. Chen SM, Cheng DS, Williams BJ, Sherrill TP, Han W, Chont M, Saint-Jean L, Christman JW, Sadikot RT, Yull FE, Blackwell TS: The nuclear factor kappa-B pathway in airway epithelium regulates neutrophil recruitment and host defence following Pseudomonas aeruginosa infection. Clin Exp Immunol 2008, 153:420-428

21. Everhart MB, Han W, Sherrill TP, Arutiunov M, Polosukhin VV, Burke JR, Sadikot RT, Christman JW, Yull FE, Blackwell TS: Duration and intensity of NF-kappaB activity determine the severity of endotoxininduced acute lung injury. J Immunol 2006, 176:4995-5005

22. Benjamin JT, Gaston DC, Halloran BA, Schnapp LM, Zent R, Prince LS: The role of integrin alpha8beta1 in fetal lung morphogenesis and injury. Dev Biol 2009, 335:407-417

23. Hawwa RL, Hokenson MA, Wang Y, Huang Z, Sharma S, SanchezEsteban J: Differential expression of MMP-2 and -9 and their inhibitors in fetal lung cells exposed to mechanical stretch: regulation by IL-10. Lung 2011, 189:341-349

24. Sanchez-Esteban J, Wang Y, Gruppuso PA, Rubin LP: Mechanical stretch induces fetal type II cell differentiation via an epidermal growth factor receptor-extracellular-regulated protein kinase signaling pathway. Am J Respir Cell Mol Biol 2004, 30:76-83

25. Livak KJ, Schmittgen TD: Analysis of relative gene expression data using real-time quantitative PCR and the 2(-Delta C(T)) Method. Methods 2001, 25:402-408

26. Miller JD, Benjamin JT, Kelly DR, Frank DB, Prince LS Chorioamnionitis stimulates angiogenesis in saccular stage fetal lungs via CC chemokines. Am J Physiol Lung Cell Mol Physiol 2010, 298: L637-L645

27. Foster JA, Curtiss SW: The regulation of lung elastin synthesis. Am J Physiol 1990, 259:L13-L23

28. Vermeulen L, De Wilde G, Van Damme P, Vanden Berghe W, Haegeman G: Transcriptional activation of the NF-kappaB p65 subunit by mitogen- and stress-activated protein kinase-1 (MSK1) EMBO J 2003, 22:1313-1324

29. Darb-Esfahani S, Sinn BV, Weichert W, Budczies J, Lehmann A, Noske A, Buckendahl AC, Muller BM, Sehouli J, Koensgen D, Gyorffy B, Dietel M, Denkert C: Expression of classical NF-kappaB pathway effectors in human ovarian carcinoma. Histopathology 2010, $56: 727-739$

30. Wendel DP, Taylor DG, Albertine KH, Keating MT, Li DY: Impaired distal airway development in mice lacking elastin. Am J Respir Cell Mol Biol 2000, 23:320-326

31. Maki JM, Sormunen R, Lippo S, Kaarteenaho-Wiik R, Soininen R, Myllyharju J: Lysyl oxidase is essential for normal development and function of the respiratory system and for the integrity of elastic and collagen fibers in various tissues. Am J Pathol 2005, 167:927-936

32. Lindahl P, Karlsson L, Hellstrom M, Gebre-Medhin S, Willetts K, Heath JK, Betsholtz C: Alveogenesis failure in PDGF-A-deficient 
mice is coupled to lack of distal spreading of alveolar smooth muscle cell progenitors during lung development. Development 1997, 124: 3943-3953

33. Bostrom H, Willetts K, Pekny M, Leveen P, Lindahl P, Hedstrand H, Pekna M, Hellstrom M, Gebre-Medhin S, Schalling M, Nilsson M, Kurland S, Tornell J, Heath JK, Betsholtz C: PDGF-A signaling is a critical event in lung alveolar myofibroblast development and alveogenesis. Cell 1996, 85:863-873

34. Margraf LR, Tomashefski JF Jr, Bruce MC, Dahms BB: Morphometric analysis of the lung in bronchopulmonary dysplasia. Am Rev Respir Dis 1991, 143:391-400

35. Bland RD: Neonatal chronic lung disease in the post-surfactant era. Biol Neonate 2005, 88:181-191

36. McCurnin DC, Pierce RA, Chang LY, Gibson LL, OsborneLawrence S, Yoder BA, Kerecman JD, Albertine KH, Winter VT, Coalson JJ, Crapo JD, Grubb PH, Shaul PW: Inhaled NO improves early pulmonary function and modifies lung growth and elastin deposition in a baboon model of neonatal chronic lung disease. Am J Physiol Lung Cell Mol Physiol 2005, 288:L450-L459

37. Bland RD, Albertine KH, Pierce RA, Starcher BC, Carlton DP: Impaired alveolar development and abnormal lung elastin in preterm lambs with chronic lung injury: potential benefits of retinol treatment. Biol Neonate 2003, 84:101-102

38. Han W, Guo C, Liu Q, Yu B, Liu Z, Yang J, Deng C: Aberrant elastin remodeling in the lungs of $\mathrm{O}(2)$-exposed newborn mice; primarily results from perturbed interaction between integrins and elastin. Cell Tissue Res 2015, 359:589-603

39. Kuang PP, Goldstein RH, Liu Y, Rishikof DC, Jean JC, JoyceBrady M: Coordinate expression of fibulin-5/DANCE and elastin during lung injury repair. Am J Physiol Lung Cell Mol Physiol 2003, 285:L1147-L1152

40. Deslee G, Woods JC, Moore CM, Liu L, Conradi SH, Milne M, Gierada DS, Pierce J, Patterson A, Lewit RA, Battaile JT, Holtzman MJ, Hogg JC, Pierce RA: Elastin expression in very severe human COPD. Eur Respir J 2009, 34:324-331

41. Shifren A, Mecham RP: The stumbling block in lung repair of emphysema: elastic fiber assembly. Proc Am Thorac Soc 2006, 3: 428-433
42. Yanagisawa H, Davis EC: Unraveling the mechanism of elastic fiber assembly: the roles of short fibulins. Int J Biochem Cell Biol 2010, 42:1084-1093

43. Papke CL, Yanagisawa H: Fibulin-4 and fibulin-5 in elastogenesis and beyond: insights from mouse and human studies. Matrix Biol 2014, 37:142-149

44. Jean JC, Eruchalu I, Cao YX, Joyce-Brady M: DANCE in developing and injured lung. Am J Physiol Lung Cell Mol Physiol 2002, 282: L75-L82

45. Loeys B, Van Maldergem L, Mortier G, Coucke P, Gerniers S, Naeyaert JM, De Paepe A: Homozygosity for a missense mutation in fibulin-5 (FBLN5) results in a severe form of cutis laxa. Hum Mol Genet 2002, 11:2113-2118

46. Yanagisawa H, Davis EC, Starcher BC, Ouchi T, Yanagisawa M, Richardson JA, Olson EN: Fibulin-5 is an elastin-binding protein essential for elastic fibre development in vivo. Nature 2002, 415: $168-171$

47. Nakamura $T$, Lozano PR, Ikeda $Y$, Iwanaga $Y$, Hinek A, Minamisawa S, Cheng CF, Kobuke K, Dalton N, Takada Y, Tashiro K, Ross J Jr, Honjo T, Chien KR: Fibulin-5/DANCE is essential for elastogenesis in vivo. Nature 2002, 415:171-175

48. Dabovic B, Robertson IB, Zilberberg L, Vassallo M, Davis EC, Rifkin DB: Function of latent TGFbeta binding protein 4 and fibulin 5 in elastogenesis and lung development. J Cell Physiol 2015, 230: 226-236

49. Alvira CM: Nuclear factor-kappa-B signaling in lung development and disease: one pathway, numerous functions. Birth Defects Res A Clin Mol Teratol 2014, 100:202-216

50. Zaynagetdinov R, Sherrill TP, Gleaves LA, Hunt P, Han W, McLoed AG, Saxon JA, Tanjore H, Gulleman PM, Young LR, Blackwell TS: Chronic NF-kappaB activation links COPD and lung cancer through generation of an immunosuppressive microenvironment in the lungs. Oncotarget 2016, 7:5470-5482

51. Londhe VA, Nguyen HT, Jeng JM, Li X, Li C, Tiozzo C, Zhu N, Minoo P: NF-kB induces lung maturation during mouse lung morphogenesis. Dev Dyn 2008, 237:328-338

52. Bry K, Whitsett JA, Lappalainen U: IL-1beta disrupts postnatal lung morphogenesis in the mouse. Am J Respir Cell Mol Biol 2007, 36:32-42 